\title{
Meningioma of the third ventricle
}

\author{
E. A. RODRIGUES \\ M.B., M.R.C.P. (U.K.)
}

A. A. H. LAWSON

M.D., F.R.C.P.E.

Medical Unit, Milesmark Hospital, Dunfermline, Fife

\begin{abstract}
Summary
A case of meningioma located in the posterior part of the third ventricle is presented. A review of the common presentations and current trends in management is included.
\end{abstract}

\section{Introduction}

Intraventricular meningiomas are rare. In two extensive reviews of 1454 cases of intracranial meningiomas seen at the Mayo Clinic between 1914 and 1967 an incidence of only $0.5 \%$ was observed (Kaplan, 1964; Kobayashi, Okazaki and MacCarty, 1971). Cushing and Eisenhardt (1938) cited only three meningiomas in the lateral ventricles among 295 cases. Only 33 cases of third ventricular meningioma have been reported in the literature to date. Thus, even amongst the intraventricular meningiomas, those located within the third ventricle are extremely uncommon. These are usually situated in the posterior part of the third ventricle and often present with symptoms and signs suggestive of pinealoma.

We present a case of a meningioma of the posterior part of the third ventricle.

\section{Case report}

A 69-year-old woman, who had previously been in good health, presented in March 1979 with a 4-month history of progressive unsteadiness, involuntary movements and memory impairment. On examination she had definite choreo-athetoid movements affecting her mouth, face and arms. Visual fields were normal and fundoscopy revealed tortuous retinal arterioles compatible with arteriosclerosis, but the discs appeared normal. She had a memory defect for recent events but other aspects of mental function were preserved. No other abnormal neurological signs were found.

Skull X-ray showed enlargement of the pituitary fossa with thinning of the dorsum sellae. An irregular

\footnotetext{
Requests for reprints to Dr Lawson
}

area of calcification measuring $1.5 \mathrm{~cm}$ across was seen in the midline. The electroencephalogram $\frac{0}{3}$ (EEG) showed no evidence of focal or paroxysmal ir abnormality. On the radio-isotope brain scan a small 0 area of increased uptake was seen situated deeply to $\underset{\infty}{\circ}$ the right of the midline in the region of the basal ganglia. Pituitary function tests were normal. Com- $\infty$ puterized axial tomography (CAT) scan revealed a $ᄋ$ high density lesion antero-superior to the pineal gland (Fig. 1), and possibly involving the gland itself, $\gg$ causing obstructive hydrocephalus at the posterior third ventricle-aqueduct junction. Third ventricular $\stackrel{5}{\rightarrow}$ prolapse was noted causing expansion of the pituis $\overrightarrow{\vec{\theta}}$ tary fossa.

The diagnosis was assumed to be pinealom causing obstructive hydrocephalus and she wo transferred to a specialist neurosurgical unit where $a$ ventriculo-peritoneal anastomosis was performed using a Pudenz valve. She subsequently received a $\%$ course of deep X-ray therapy to the pineal gland.

When seen for review in July, 1979, she was $\overrightarrow{\vec{A}}$ symptom-free with no abnormal neurological signs $\frac{3}{3}$ on examination.

In June, 1980 the patient complained again of difficulty with recent memory and increasing ataxia. The ventriculoperitoneal shunt was found to be 3 . malfunctioning. Repeat CAT scan, however, showed $\overline{0}$ no new change and there was no progressive growth of the tumour.

She was readmitted to the medical unit in August, $₹$ 1980 having collapsed with a left hemiparesis and she 을 finally succumbed 3 weeks later to a pulmonary embolus.

At post-mortem examination the cause of death was confirmed. Neuropathological examination re- $\sigma$ vealed chronic cerebrovascular disease with multiple $\tilde{O}$ old cerebral infarcts and a $2-\mathrm{cm}$ spherical, partly $\mathbb{\omega}^{N}$ calcified, lobulated greyish tumour located posteriorly in the third ventricle embedded in the thalamus on each side. It extended as far anteriorly as the mass $\underset{\varnothing}{\varnothing}$ intermedia and projected posteriorly between the $\stackrel{\mathscr{C}}{+}$ splenium of the corpus callosum and the pineal gland $T$ which was normal (Fig. 2). 


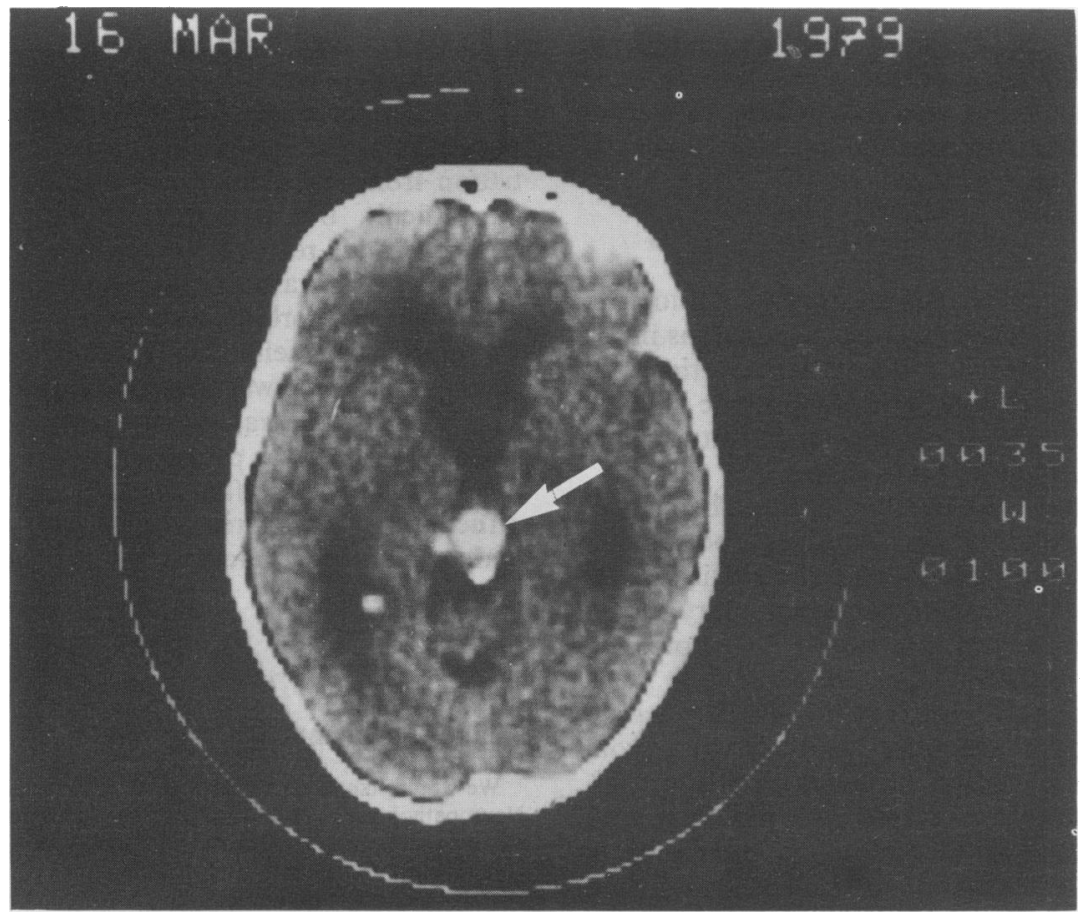

FIG. 1. CAT scan showing meningioma (arrowed) of the third ventricle.

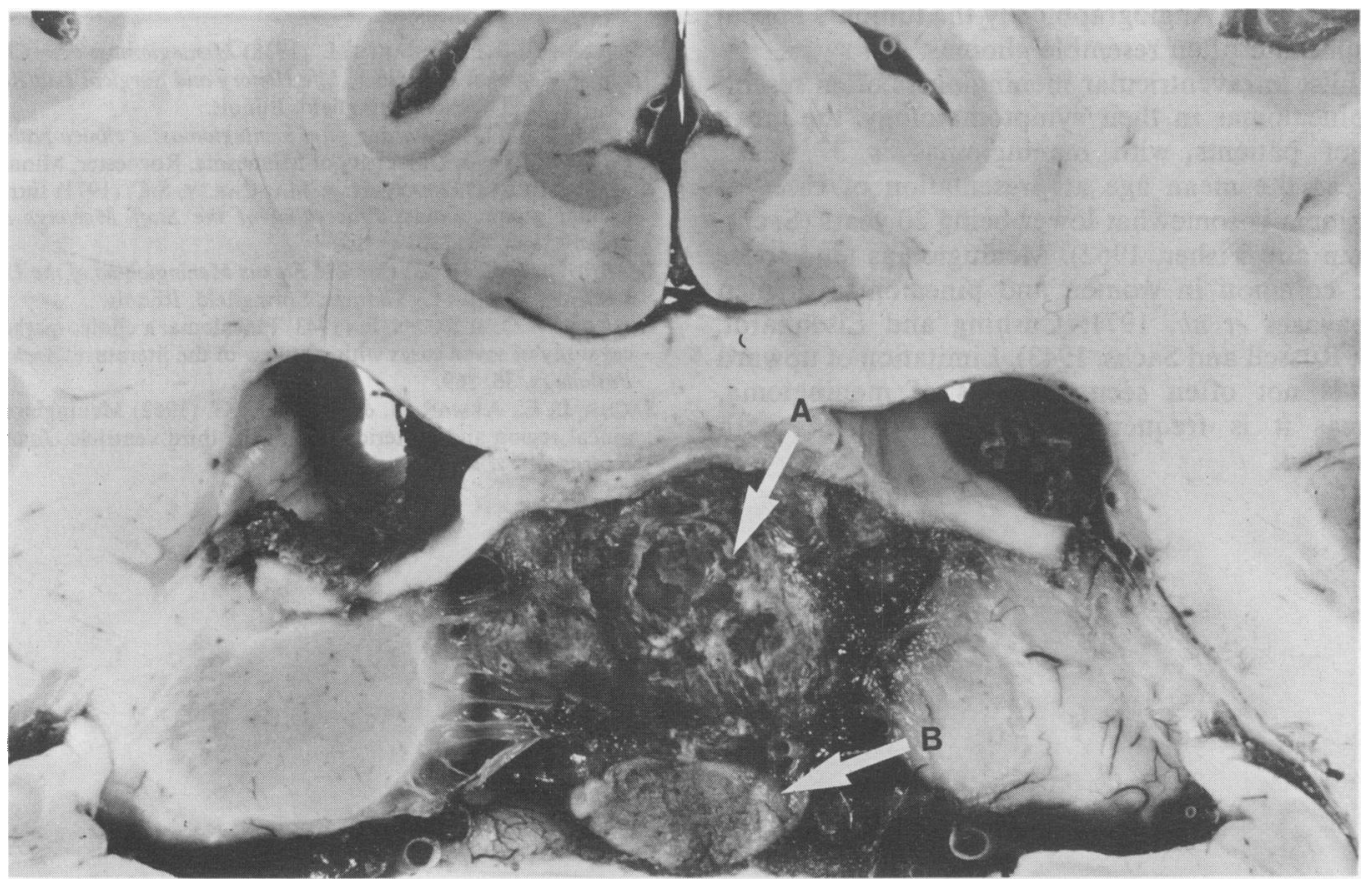

FIG. 2. Section of brain at third ventricle level showing site of intraventricular meningioma (A) and pineal gland (B). 
Microscopically the tumour was a meningioma consisting of small 'arachnoidal' cellular whorls lying in dense fibrous tissue and containing numerous psammoma bodies with irregular calcified trabecular masses in the fibrous stroma.

\section{Discussion}

Intraventricular meningiomas are thought to arise from neoplastic mesenchymal cell populations in the tela choroidea. Those of the third ventricle are usually located posteriorly and often mimic pinealomas, and other lesions causing raised intracranial pressure in their clinical presentation.

Initial symptoms frequently include headaches with associated nausea and vomiting, personality change, homonymous hemianopia and ataxia (Kobayashi et al., 1971). Tremor and involuntary movements, as in our case, have also been noted presumably due to pressure by the tumour on the basal ganglia. In Ladenheim's series (1963) 8\% had tremor. Plain skull X-rays are often normal apart from exhibiting signs of raised intracranial pressure although focal calcification within the tumour has been recorded. Electroencephalography is unhelpful in diagnosis as is examination of cerebrospinal fluid (Kobayashi et al., 1971). Pneumoencephalography has, in the past, been useful in localizing and determining the size of the tumour but this potentially hazardous investigation has been superseded by the CAT scan. Angiographically the tumours appear vascular and often resemble gliomas.

Whilst intraventricular meningiomas often resemble pinealomas in their symptomatology, the mean age of patients with meningiomas is 37 years, whereas the mean age at presentation of cases of pinealoma is somewhat lower being 20 years (Sachs, Avman and Fisher, 1962). Meningiomas tend to be more common in women and pinealomas in men (Kobayashi et al., 1971; Cushing and Eisenhardt, 1938; Russell and Sachs, 1943). Limitation of upward gaze is not often seen in cases of meningioma, whereas it is frequently found in patients with pinealoma.
There has been a tendency for lesions in the pineal region to be treated by ventriculo-cisternostomy or third ventriculostomy followed by radiotherapy without pathological verification of the tumour. Differen- $\stackrel{.}{\Rightarrow}$ tiation from pinealomas and thalamic tumours may $\stackrel{\rho}{\rightarrow}$ be difficult, but is important despite their deep $\overline{0}$ location and relative inaccessability, as surgical 흐 treatment of intraventricular meningiomas is associ- $\frac{\bar{\sigma}}{\bar{\sigma}}$ ated with low morbidity and mortality (Kobayashi et $\mathbb{\varnothing}$ al., 1971; Ladenheim, 1963). In our patient exploration of the tumour was decided against because of her frail state and generalized cerebrovascular disease. In $\vec{\circ}$ general, however, as prognosis is good in experienced $\overrightarrow{\vec{H}}$ hands and since differentiation can otherwise be difficult, a more aggressive approach to the surgical $\bar{D}$ management of tumours in this location is to be $\frac{3}{3}$ encouraged.

\section{Acknowledgments}

We would like to thank Dr A. J. F. Maloney, Senior Lecturer in Neuropathology, University of Edinburgh, for providing the neuropathological photographic material and for his helpful advice. Our thanks also to Mr J. F. Shaw, Consultant Neurosurgeon, Western General Hospital, Edinburgh, for permission to publish this $\frac{c}{\omega}$ case.

\section{References}

CUSHING, H. \& EISENHARDT, L. (1938) Meningiomas: their Classification, Regional Behaviour, Life History and Surgical End Results. Charles C. Thomas, Springfield, Illinois.

KAPLAN, E.S. (1964) Parasaggital meningiomas: a clinico-pathological study. Thesis, University of Minnesota, Rochester, Minnesota. $\overrightarrow{\vec{O}}$

Kobayashi, S., OKAZAKI, H. \& MACCARTY, S.C. (1971) Intraventricular meningiomas. Proceeding of the Staff Meetings of the Mayo Clinic, 46, 735.

LADENHEIM, J.C. (1963) Choroid Plexus Meningiomas of the Lateral Ventricle. Charles C. Thomas, Springfield, Illinois.

RusSEll, W.O. \& SACHS, E. (1943) Pinealoma: a clinico-pathological study of seven cases with a review of the literature. Archives of Pathology, 35, 869.

SACHS, JR E., AVMAN, N. \& FiSher, R.G. (1962) Meningiomas of pineal region and posterior part of the third ventricle. Journal of Neurosurgery, 19, 325. 